\title{
Actinomyces israelii
}

National Cancer Institute

\section{Source}

National Cancer Institute. Actinomyces israelii. NCI Thesaurus. Code C86108.

A species of anaerobic, Gram positive, rod shaped bacteria assigned to the phylum

Actinobacteria. This bacteria hydrolyzes esculin, produces acid from xylose and is urease and catalase negative. A. israelii is found in the flora of the human oral and nasopharyngeal tract and in animals and is the most frequent cause of actinomycosis in humans. 